\title{
Assessment of Contraceptive Use and Associated Factors among HIV Positive Women in Bahir-Dar Town, Northwest Ethiopia
}

\author{
Henok Gebreyohaness Kebede¹, Honelgn Nahusenay², Yemane Birhane², \\ Dawit Jember Tesfaye ${ }^{3}$ \\ ${ }^{1}$ Clinton Health Access Initiative, Addis Ababa, Ethiopia \\ ${ }^{2}$ Addis Continental Institute of Public Health, Addis Ababa, Ethiopia \\ ${ }^{3}$ Department of Clinical Nursing, Hossana College of Health Sciences, Hossana, Ethiopia \\ Email: Hinaabt1@gmail.com, h.nahu2000@gmail.com, yemaneberhane@gmail.com, \\ devanhijember@gmail.com
}

Received 22 September 2015; accepted 10 October 2015; published 16 October 2015

Copyright (C) 2015 by authors and OALib.

This work is licensed under the Creative Commons Attribution International License (CC BY).

http://creativecommons.org/licenses/by/4.0/

(c) (i) Open Access

\section{Abstract}

Mother to child HIV transmission accounts for over 95 percent of childhood infections. However, many HIV Positive women still become pregnant. Achieving the goal "HIV free generation" would only be a dream, unless a strong emphasis is given to prevention of pregnancy among HIV positive women. Therefore, we aimed to assess family planning utilization and associated factors among HIV positive women enrolled at ART program in Bahir-dar town health facilities. Institution based cross-sectional study was conducted by interviewing 420 sexually active HIV positive women using systematic random sampling technique. Descriptive, bivariate, and multivariate logistic regression methods were used to analyze utilization of contraceptives and the factors associated with it. About $80 \%$ of the study participants are using at least one type of contraceptive method at the time of study. Injection (54.7\%) and condom (18.6\%) are the most commonly used contraceptive methods. HIV positive women with Primary [AOR: 3.06, 95\% C.I: 1.42, 6.59] and secondary [AOR: 2.35, 95\% C.I: 1.08, 5.57] educational were more likely to use contraceptive. Participants who decide about contraceptive use by themselves were less likely to use contraceptive than who decides jointly with their partner [AOR: 0.29, 95\% C.I: 0.14, 0.63]. Women counseled about FP by ART provider [AOR: 2.63, 95\% C.I: 1.46, 4.73] and participants who have no fertility desire [AOR: 3.11, 95\% C.I: 1.46, 6.64] were more likely to use contraceptive. Those who have undecided opinion about the safety of contraceptive methods [AOR: $0.23,95 \%$ C.I: $0.10,0.53$ ] and women partners who have no fertility desire are less likely [AOR: 0.39, 95\% C.I: $0.17,0.91$ ] to use contraceptive. The uptake of contraceptive use among HIV positive women is high. However, the use of most long acting contraceptive methods is still very low. Moreover, significant proportions of women 
have encountered pregnancy after they know their HIV status. The findings of this study highlight, FP counseling inline with effective discussion about child bearing and pregnancy issues is important in order to increase the uptake of contraceptive utilization among HIV positive women.

\title{
Keywords
}

\section{Human Immune Deficiency Virus (HIV), Contraceptive, HIV Positive Women, Associated Factors}

\author{
Subject Areas: Epidemiology
}

\section{Introduction}

The burden of pregnancy among HIV positive women is high among Sub-Saharan Africa (SSA), where reproductive age group women account for $60 \%$ of all adult HIV infections [1]. Among 1.4 million HIV positive pregnant women in low and middle-income countries in 2008, greater than $90 \%$ were found in SSA. And an estimated 430,000 children were newly infected with HIV in the same year, and over $90 \%$ of them is through mother-to-child transmission (MTCT) [2]. Sub-Saharan Africa also has high fertility rates with an estimated 14 million unintended pregnancies annually and high unmet need for contraception [3].

In addition, the increasing feminization of the global HIV epidemic is widely recognized; nearly half of the 38.6 million people living with HIV today are women [4]. Due to the increased life expectancy and improved quality of care after advent of antiretroviral therapy (ART) over the last decades, many HIV Positive women are seen with increased desire and intention to become pregnant globally. However, unlike developed countries in which breakthroughs pregnancy care have reduced the risk of vertical transmission to less than $1 \%$ [5], pregnancy among HIV positive women is still an issue of public health importance in resource poor settings because of its poor maternal outcomes and increased prevalence pediatric HIV infections. Hence, family planning (FP) for seropositive women, as prevention of unintended pregnancies and reduction vertical transmission of HIV, is considered one of the ten priority areas of the United Nations Joint Program on HIV/AIDS. Also the World Health Organization, lists preventing unintended pregnancies among people living with HIV as second pillar of preventing mother-to-child transmission (PMTCT). In addition it helps for prevention of HIV transmission to uninfected partners [1] [2].

Despite the low contraceptive prevalence, several studies suggest that the current levels of contraceptive use in SSA may already be preventing 22\% (or 173,000) of HIV-positive births annually. And if the unmet need for contraceptive is met among HIV infected women an additional 160,000 HIV-positive births could be averted every year [6].

Besides the benefits in averting HIV positive births it is also a cost effective strategy. For example, Ethiopia could gain an estimated average annual net saving of US $\$ 360,000$ by providing family planning to HIV positive women than providing ARV prophylaxis in [7]. Ethiopia seems far reaching towards achieving the target to eliminate MTCT of HIV by 2015, with the current poor reproductive health outcomes such as; high prevalence of HIV among reproductive age women (1.9\% among general and 5.2\% among urban women), high total fertility rate (4.8\%), low contraceptive utilization (29\%) [8], and poor PMTCT outcomes such as; low ARV prophylaxis coverage (24\%) and significant proportion of MTCT (30\%) [9], unless a due emphasis is given towards prevention of pregnancy among HIV infected women.

Though Ethiopian national plans and guidelines are encouraging the integration family planning with HIV services, as a key intervention to reduce HIV transmission, but evidence shows that prevention of unintended pregnancy through family planning as the second pillar of PMTCT becomes the neglected area. Also, many HIV positive women are still encountering unintended pregnancies with a concomitant risk of MTCT and risk of pregnancy related morbidity and mortality due to low family planning uptake and utilization of service.

Despite several studies conducted in various African countries indicate that the individual desires, reproductive factors, societal expectations and medical interventions (HAART and PMTCT) in line with health service factors are the predictor for contraceptive utilization among HIV positive women. However, there are limited studies conducted in Ethiopia, particularly at Bahir-dar town which try to assess the magnitude of contraceptive 
utilization and associated factors among sexually active HIV positive women. Hence, in order to clarify the demand, and aid with appropriate health services planning for this population, this study aims to assess the contraceptive utilization and factors related with their preferences and hindrances in uptake and utilization of FP services in the context of ART service provision among sexually active HIV Positive women enrolled at governmental facilities of Bahir-dar health town.

\section{Methods}

\subsection{Study Design and Setting}

We conducted a cross sectional study at Bahir Dar town health facilities ART clinics (i.e. Felegehiwot Referral Hospital, HAN Health Center, Abay Health Center and Bahir-dar Health Centre)from July to August 2013. The town is located $565 \mathrm{~km}$ far from Addis Ababa, the capital city of Ethiopia. According to the Felegehiwot Referral Hospital 2013 report, 5611 reproductive age group women were enrolled in chronic care (3111 on ART and 2500 on Pre-ART care). Among this 113 HIV positive women had been ever pregnant since they enrolled in chronic care. In the health centers 1031, 412 and 1587 reproductive age group women were enrolled in chronic care clinic of HAN Health Center, Abay Health Center and Bahir-dar Health Centre respectively. Out of these in HAN Health Center 95 (9.2\%), Abay Health Center (15.3\%), in Bahir-dar Health Centre 266 (16.7\%) HIV infected women had been ever pregnant since they enrolled in chronic care.

\subsection{Selection of Study Participants}

The source populations were all reproductive age group (18 - 49) women who are enrolled at chronic HIV care service and are in active follow up during the study period at three health centers and one referral Hospital found in Bahir-dar town. The sample size was calculated using single population proportion formula with the assumption of estimated proportion of contraceptive use 53.5\% [10], 95\% confidence level $(z=1.96)$ and 5\% margin of error $(\mathrm{d}=0.05)$. Therefore, considering $10 \%$ non-response rate the sample size was calculated to be 420 . Monthly, an average of 3,282,885, 520 and 246 reproductive age group woman attend ART clinic of Felegehiwot hospital, Bahir-dar Health Center, HAN Health Center and Abay Health Center respectively. Proportional allocation was employed to the respective health facilities and systematic sampling was used to select the study subjects. The sampling interval was calculated to be 12 . Therefore, every $12^{\text {th }}$ client attended the ART clinics were included in the study until the sample size reaches its final size. Sexually active HIV positive women aged (18 - 49), who have at least two follow up in ART/chronic HIV care clinic, mentally and physically competent, non-pregnant, willing to provide informed consent during the data collection period were included in the study. Those who have history of hysterectomy and medically confirmed fecundity were excluded from the study.

\subsection{Data Collection}

A structured questionnaire (Appendix 1) was used to collect the data. First the questionnaire was prepared in English and then translated in to Amharic language. The Amharic version was back translated to English to check for consistency and ensure the quality of translation. The questionnaire was pre-tested in 29 HIV positive women in Bure Health Center and in Aflagat General Private Hospital. The result of pre-test is used to estimate the time allowed for each interview and to conduct some modifications in the questionnaire like; the logical flow of the questionnaire, excluding some unnecessary questions, changing the wording of questions. Two days training was given on basic technique of conducting interview, objective, content and rationale of the study including research ethical principles. In addition a one hour debriefing session with respective health facility ART nurses was conducted on the purpose of the study, developed questionnaire and why they are not recruited as a data collector to smooth the facilitation of selecting and linking eligible participants to data collectors.

\subsection{Data Analysis}

Data were entered in to Epi info Version 3.5.1 and analyzed using SPSS version 20 software. Descriptive statistics, frequency distributions such as percentages and proportions were computed for different variables. Bivariate analysis was also performed to see if there is any association between two variables and to select candidate variables for multivariate analysis. Multivariate logistic regression analysis was employed to identify factors 
associated with current contraceptive use and to control the confounding effects of variables. P-value of $<0.05$ was used as a cut of point to affirm statistically significant association between independent variable and utilization of contraceptive methods.

\subsection{Ethical Clearance and Consideration}

Ethical clearance was obtained from Ethical review committee of University of Gondar and Amhara Regional Health Bureau. A formal permission letter was written to each selected health facilities from Amhara Regional Health Bureau. Informed consent was obtained from each participants and the information obtained from the study participants kept confidential.

\section{Results}

\subsection{Socio-Demographic Characteristics of the Study Population}

Of the total 420 sampled study subjects, 416 participated in this study giving the response rate $99.04 \%$. Most of the study participants 384 (92.3\%) were residing in urban area. The mean $( \pm$ SD) age of the participants was 30.2 $( \pm 4.9)$ and majority of them 144 (34.6\%) falls in the age group of 25 - 29 year. Most 340 (81.7\%) of the participants are either married or living in unions with their partner. Around 169 (40.6\%) of the respondents had no formal education and only $53(12.7 \%)$ have an educational status above secondary education. About 159 (38.2\%) of the participants are either with no occupational status or house wife.

Of the total, 181 (43.5\%) of the participants had a total monthly family income greater than 1000 Ethiopian birr (ETB) (50 USD). The median income of the participant was 1020 ETB (51 USD) (minimum of 100 ETB (5 USD) and maximum of 10,200 ETB (510 USD). Among the 365 participants who have sexual partner/spouse, $79(21.8 \%)$ of their partners have no formal education and $71(19.6 \%)$ of them have an educational status of above secondary education (Table 1).

\subsection{Selected Background Characteristics of Respondents}

Knowledge about family planning was found to be universal among this study participant 406 (97.6\%). Nine out of 10 participants have knowledge about injection method 369 (90.9\%), followed by pills 292 (71.9\%), condom 256 (63.1\%), implant 252 (62.2\%) and IUD 219 (53.9\%). The major source of information about family planning are health professionals 354 (87.2\%) and mass media 201 (49.5\%). Among all participants, majority 292 (70.2\%) of them have a positive attitude about safety of most contraceptive methods for use by HIV positive women. Only 74 (17.8\%) of the participants have complete knowledge about PMTCT, but majority of the study participants 396 (90.9\%) and 350 (84.1\%) do know at least one route of MTCT and PMTCT intervention, respectively. Majority of the participants 344 (82.7\%), perceived their current health status as either a very good or good condition.

A significant 111 (26.7\%) proportion of them have ever become pregnant since they knew their HIV status, and among these $16(14.4 \%)$ of them become pregnant at least two times, since they know their HIV status. Among the 127 sum of these pregnancies, 21 (16.5\%) of them were unwanted pregnancies. About 235 (56.5\%) of the respondent have a desire to have a child in the future, while 161 (38.7\%) and 20 (4.8\%) of them do not have fertility desire and not sure about their desire respectively.

\subsection{Family Planning Utilization}

In this study, out of the total 416 HIV-positive women of reproductive age living in Bahir-dar, Ethiopia, we found that 333 (80\%) [95\% C.I: $(76 \%, 84 \%)$ ] are currently using at least one type of contraceptive method for the purpose of either limiting or spacing birth. Among the current contraceptive users; injection 182 (54.7\%), condom 173 (52.0\%) and implant 59 (17.7\%) are the most commonly used modern contraceptive methods, while pills 22 (6.7\%), IUD 6 (1.8\%) calendar 2 (0.6\%) are the least commonly used methods.

Among the 173 condom users; 111 (64.2\%) of them use condom with one additional contraceptive method (dual method) and 62 (35.8\%) of them use condom alone as contraceptive method. Most of the respondents (93.8\%) choose the current contraceptive method they are using now, because of their perceived suitability to their health 222 (67.5\%) and the advice of health professionals (26.3\%). 
Table 1. Socio-demographic characteristics of HIV positive women who are in chronic follow up care, in Bahir-dar, August 2013.

\begin{tabular}{|c|c|c|}
\hline Characteristics $(\mathrm{N}=416)$ & Frequency & Percent \\
\hline \multicolumn{3}{|l|}{ Age } \\
\hline $18-24$ & 42 & 10.1 \\
\hline $25-29$ & 144 & 34.6 \\
\hline $30-34$ & 123 & 29.6 \\
\hline $35-39$ & 90 & 21.6 \\
\hline$\geq 40$ & 17 & 4.1 \\
\hline \multicolumn{3}{|l|}{ Residence } \\
\hline Urban & 384 & 92.3 \\
\hline Rural & 32 & 7.7 \\
\hline \multicolumn{3}{|l|}{ Educational Status } \\
\hline No Education & 169 & 40.6 \\
\hline Primary & 100 & 24 \\
\hline Secondary & 91 & 21.9 \\
\hline Above secondary & 53 & 12.7 \\
\hline \multicolumn{3}{|l|}{ Ethnicity } \\
\hline Amhara & 394 & 94.7 \\
\hline Others $^{*}$ & 18 & 4.8 \\
\hline \multicolumn{3}{|l|}{ Religious Status } \\
\hline Orthodox & 366 & 88 \\
\hline Muslim & 32 & 7.7 \\
\hline Protestant & 18 & 4.3 \\
\hline \multicolumn{3}{|l|}{ Occupational Status } \\
\hline No occupation & 159 & 38.2 \\
\hline Daily laborer & 76 & 18.3 \\
\hline Merchant & 70 & 16.8 \\
\hline Government/private employee & 72 & 17.3 \\
\hline Other $^{* *}$ & 37 & 8.9 \\
\hline \multicolumn{3}{|l|}{ Marital Status } \\
\hline Married/Cohabited partner & 340 & 81.7 \\
\hline Non-cohabited partner & 23 & 5.5 \\
\hline Separated/widowed/divorced & 24 & 5.8 \\
\hline \multicolumn{3}{|c|}{ Total Monthly Family Income (in ETB) } \\
\hline$<300$ & 26 & 6.3 \\
\hline $301-600$ & 67 & 16.1 \\
\hline $601-1000$ & 94 & 22.6 \\
\hline$>1000$ & 181 & 43.5 \\
\hline Don’t know & 41 & 9.9 \\
\hline
\end{tabular}

*Others: Tigray, Oromo, Gurage and Wolaita. ${ }^{* *}$ Others: sex worker, farmer, waitress, student, house servant, associate leader \& parking. 
Among the 416 participants, 300 (72.1\%) and 365 (87.7\%) have also reported ever use of FP method before HIV diagnosis and after HIV diagnosis, respectively. Injection 197 (65.70\%) and Pills 107 (35.75\%) were the most commonly used ever contraceptive methods before HIV diagnosis, while injection 207 (56.7\%) and condom 181 (49.5\%) are the most commonly used ever contraceptive methods after HIV diagnosis. There is an observed pattern of method use shift, with regard to HIV status (Figure 1).

Among those who are not using contraceptive currently 83 (20\%), the most common reason not to use any contraceptive method was the desire to have a child in the future 49 (59\%), followed by fear of side effects 13 (15.7\%). And only 32 (38.6\%) of them have a desire to use family planning in the future. Injection $19(59.4 \%)$ is the most desired contraceptive method in the future, followed by Condom 10 (31.3\%), Implant 7 (21.9\%), pills 1 (3.1\%).

And among those participants who do not have fertility desire 181 (43.5\%) in the future, $13.7 \%$ of them are not using any contraceptive currently and $17.4 \%$ of them use condom as a contraceptive method currently, while only $16.1 \%$ of them are using most effective long term contraceptive methods (Figure 2).

\subsection{Source of Family Planning}

Among the 333 participants who are using any contraceptive method currently, only 38 (11.4\%) of clients mentioned ART clinic/Chronic HIV care clinic as their source of contraceptive they are using now. And more than half $(54.5 \%)$ of them mentioned they obtained their current contraceptive method from sources outside the health facilities. Despite this, majority (43.6\%) of them mentioned ART clinic/chronic HIV care clinic as their preferred source to obtain contraceptive method in the future, followed by FP clinic in the same facility 31.2\% (Table 2). In addition 402 (97.1\%) of the participants has a positive attitude about integration of FP service at ART clinic.

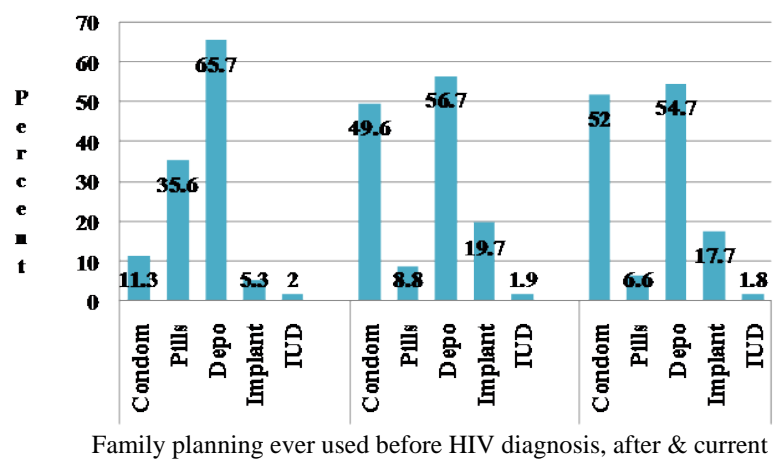

Figure 1. Type of contraceptive method by, ever used, current use and future desire among HIV positive women who are in chronic follow up care in Bahir-dar, August 2013.

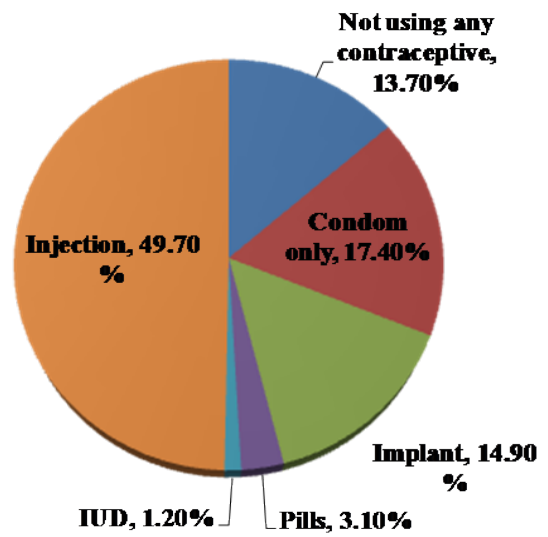

Figure 2. Type and use of contraceptive among HIV positive women who donot have fertility desire. 
Table 2. Source of current contraceptive method and preferred place for FP service by HIV positive women in chronic follow up care, Bahir-dar, August, 2013.

\begin{tabular}{llll}
\hline Current source of FP $(\mathbf{n}=\mathbf{3 3 3})$ & $\mathbf{N}(\mathbf{\%})$ & $\begin{array}{l}\text { Preferred source to obtain FP in the } \\
\text { future }(\mathbf{n}=\mathbf{3 6 5})^{*}\end{array}$ & $\mathbf{N}(\mathbf{\%})$ \\
\hline ART clinic/follow up clinic & $38(11.4)$ & ART clinic/follow up clinic & $159(43.6)$ \\
FP in the facility & $83(24.9)$ & FP in the facility & $114(31.2)$ \\
Other governmental health facilities & $112(33.6)$ & Other governmental health facilities & $60(16.5)$ \\
Private hospital/clinic & $56(16.8)$ & Private hospital/clinic \\
NGO clinic & $17(5.1)$ & NGO clinic & $13(3.6)$ \\
Pharmacy/drug vendor & $13(3.9)$ & Pharmacy/drug vendor & $8(2.2)$ \\
Shop & $10(3.0)$ & Shop & $3(0.8)$ \\
Other & $4(1.2)$ & Other & $5(1.4)$ \\
\hline
\end{tabular}

N.B ${ }^{*}$ includes those who are current users and not using FP currently but intend to use in the future.

Out of the total current contraceptive users, 76 (22.8\%) of the participants mentioned that they have paid during obtaining their current contraceptive method. The median cost for obtaining their last contraceptive method is seven Ethiopian birr (minimum 2 birr and maximum 50 birr). Among those who mentioned they have paid for contraceptive 46 (60\%) and 13 (17.1\%) of them were obtain their method from private health clinic/hospital and NGO clinics respectively, while 5 (6.6\%) of them mentioned government facilities.

Among the total 416 participants, 287 (69\%) have received counseling about family planning methods from the ART provider/counselor. Condom 241 (84\%) takes the lead by being the most common family planning method counseled by the ART provider/counselor followed by injectable 156 (54.4\%).

In this study there is an observed similarity between the most common methods counseled by the ART provider/counselor and the most common methods used among the study participants. In addition 272 (65.4\%) have ever discussed about child bearing and pregnancy issue with ART provider/counselor, of which majority 232 (85.3\%) of them still want further discussion with the provider.

Out of the 416 participants, 186 (44.7\%) of them mentioned that they have ever been provided with a contraceptive method from the ART clinic/chronic follow up care clinic, and the most common contraceptive method provided from ART/chronic follow up care clinic is condom 159 (85.5\%) (Table 3).

Despite the low proportion (44.7\%) of family planning provision from ART clinic/chronic follow up care clinic, only 40 (9.6\%) of participants, were referred for family planning service to other sites from ART clinic, including the family planning clinic in the same facility where they are receiving chronic HIV/AIDS care.

\subsection{Factors Associated with Current Contraceptive Utilization in HIV Positive Women}

The finding from the multivariate analysis indicates that; those participants with educational status of primary and secondary are more likely to use contraceptive than those who have no formal educational status [AOR: 3.06, 95\% C.I: 1.42, 6.59] and [AOR: 2.35, 95\% C.I: 1.08, 5.57], respectively. And as compared to those participants who decides about contraceptive use jointly with their partner, those who decide by themselves are less likely to use contraceptive [AOR: 0.29, 95\% C.I: 0.14, 0.63]. Compared to those participants who have not been counseled about FP by their ART provider/counselor, those who have been counseled are more than two and half times more likely to use contraceptive [AOR: 2.63, 95\% C.I: 1.46, 4.73]. Those who have undecided opinion about the "safety of most contraceptive methods to HIV positive women" are less likely to use contraceptive, compared to those who have positive attitude [AOR: 0.23, 95\% C.I: 0.10, 0.53]. Compared to those participants whose partners have a fertility desire, those whose partners have no fertility desire are less likely to use contraceptive currently [AOR: 0.39, 95\% C.I: 0.17, 0.91]. Those participants who have no fertility desire are more likely to use contraceptive than those who have fertility desire [AOR: 3.11, 95\% C.I: 1.46, 6.64] (Table 4).

\section{Discussion}

The finding of this study indicates that uptake of current contraceptive use was $80 \%$. In contrast the study 
Table 3. Distribution of contraceptive methods ever provided to HIV positive women from ART clinic/chronic HIV follow care, by type of health facility, in Bahir-dar, August 2013.

\begin{tabular}{|c|c|c|c|c|c|c|c|}
\hline \multirow[t]{2}{*}{ Facility type } & \multicolumn{3}{|c|}{ Provision of contraceptive from ART clinic } & \multicolumn{4}{|c|}{ Type of contraceptive method Provided } \\
\hline & Yes & No & Total & Condom & Injection & Implant & Pills \\
\hline All health centers & $85(58.2)$ & $61(26.5)$ & $146(41.8)$ & $67(78.8)$ & $26(30.6)$ & $5(5.9)$ & $4(4.7)$ \\
\hline Hospital & $101(37.4)$ & $169(62.6)$ & $270(64.9)$ & $92(91.1)$ & $7(6.9)$ & $2(2.0)$ & $4(4.0)$ \\
\hline Total & $186(44.7)$ & $230(55.3)$ & $416(100)$ & 159 (85.5) & 33 (17.7) & $7(3.8)$ & $8(4.3)$ \\
\hline
\end{tabular}

Table 4. Multivariable logistic regression model predicting contraceptive use among HIV positive women attending ART Clinic of Bahir dar town health facilities, North Ethiopia, 2013.

\begin{tabular}{|c|c|c|c|c|}
\hline \multirow{2}{*}{ Predictors } & \multicolumn{2}{|c|}{ Contraceptive use } & \multirow{2}{*}{ COR, 95\% C.I } & \multirow{2}{*}{ AOR, 95\% C.I } \\
\hline & Yes & No & & \\
\hline \multicolumn{5}{|c|}{ Educational status } \\
\hline No formal education & $123(72.8)$ & $46(27.2)$ & 1 & 1 \\
\hline Primary & $84(84.0)$ & $16(16.0)$ & $1.96(1.04,3.70)$ & $3.06(1.42,6.59)^{* *}$ \\
\hline Secondary & $82(90.1)$ & $9(9.9)$ & $3.41(1.58,7.34)$ & $2.35(1.08,5.57)^{* *}$ \\
\hline Above secondary & $41(77.4)$ & $12(22.6)$ & $1.28(0.62,2.64)$ & $0.97(0.41,2.29)$ \\
\hline \multicolumn{5}{|c|}{ Decision about FP use } \\
\hline Joint & $252(86.3)$ & $40(13.7)$ & 1 & 1 \\
\hline Me only & $31(58.5)$ & $22(41.5)$ & $0.23(0.12,0.45)$ & $0.29(0.14,0.63)^{*}$ \\
\hline Partner only & $11(68.8)$ & $5(31.2)$ & $0.35(0.12,1.05)$ & $0.42(0.11,1.67)$ \\
\hline \multicolumn{5}{|c|}{ Opinion about safety of FP to HIV + women } \\
\hline Positive & $252(86.3)$ & $40(13.7)$ & 1 & 1 \\
\hline Neutral & $21(46.7)$ & $24(53.3)$ & $0.14(0.07,0.27)$ & $0.23(0.10,0.53)^{*}$ \\
\hline Negative & $59(75.6)$ & $19(24.4)$ & $0.49(0.27,0.91)$ & $0.27(0.24,1.09)$ \\
\hline \multicolumn{5}{|c|}{ Counseled about FP } \\
\hline No & 90 (69.8) & $39(30.2)$ & 1 & 1 \\
\hline Yes & $243(84.7)$ & $44(15.3)$ & $2.39(1.46,3.92)$ & $2.63(1.46,4.73)^{*}$ \\
\hline \multicolumn{5}{|c|}{ Fertility desire } \\
\hline Yes & 177 (75.3\%) & $58(24.7)$ & 1 & 1 \\
\hline No/not sure & $156(86.2)$ & 25 (13.8) & $2.05(1.22,3.43)$ & $3.11(1.46,6.64)^{*}$ \\
\hline \multicolumn{5}{|c|}{ Knowledge about PMTCT } \\
\hline No & 266 (77.8) & $76(22.2)$ & $0.37(0.16,0.83)$ & $0.41(0.16,1.00)$ \\
\hline Yes & $67(90.5)$ & $7(9.5)$ & 1 & 1 \\
\hline \multicolumn{5}{|c|}{ Partner desire for child } \\
\hline Yes & $187(82.0)$ & $41(18.0)$ & 1 & 1 \\
\hline No/don't know & 109 (81.3) & 25 (18.7) & $0.74(0.53,1.03)$ & $0.39(0.17,0.91)^{* *}$ \\
\hline \multicolumn{5}{|c|}{ Currently alive child } \\
\hline None & $64(67.4)$ & $31(32.6)$ & 1 & 1 \\
\hline 1 & $104(78.2)$ & $29(21.8)$ & $1.74(0.96,3.15)$ & $1.42(0.70,2.87)$ \\
\hline 2 & $93(88.6)$ & $12(11.4)$ & $3.75(1.79,7.86)$ & $2.78(1.15,6.72)^{* *}$ \\
\hline$>2$ & $71(86.6)$ & $11(13.4)$ & $3.12(1.45,6.73)$ & $2.79(1.06,7.39)^{* *}$ \\
\hline
\end{tabular}

${ }^{*}$ P-value $<0.05 ;{ }^{* *}$ P-Value $<0.001$. 
conducted in Gondar University Hospital, Ethiopia, reported 25.7\% Contraceptive Prevalence Rate (CPR) among HIV positive women [11]. Our finding is also higher than the general urban women population in Ethiopia 53\% [8]. The variation could be the frequent counseling that HIV positive women undergo in ART clinics and could be a sign of positive behavioral change, as also observed in other similar studies [12]-[14]. However some other studies conducted in Ethiopia and other countries have also indicated CPR as high as 58\% to 95\% in their findings [14]-[18].

The higher rate of current and ever contraceptive use after HIV diagnosis could be considered as a promising finding. However, still $26.7 \%$ of the women participated in this study have ever been pregnant since they know their HIV status. Of these $16.5 \%$ of the total pregnancies were unwanted. Similar large number of unintended pregnancies among HIV-positive women, despite higher uptake of FP has also been reported in studies conducted Ethiopia [16], Malawi [19], Uganda [14], Kenya [20] and other countries [21].

The possible explanation for the observed paradox between the high FP uptake and high pregnancy rate in this study might be due to $31.1 \%$ of the participants who do not have fertility desire are either not using any contraceptive currently or use condom only. Although condoms provide dual protection from HIV transmission and acquisition, as well as pregnancy prevention, the effectiveness reduces when the condoms are not used correctly and consistently [22]. Thus, some women using condoms and those with no fertility desire but have unmet need for FP is at risk of an unintended pregnancy. The observed high fertility desire of this study $43.5 \%$ could also be a factor for all kinds of pregnancies, whether intended or unintended.

More than half of this study participant was used injection $54.7 \%$ and condom only $18.9 \%$ and the use of other long acting methods, including implant is very low and even insignificant in some methods like; Intra Uterine Device (IUD), tubal ligation, and vasectomy. This finding is consistent with the study conducted in other countries [12] [14]-[21] [23] [24]. It was indicted that the breadth of method mix is most commonly affected by factors like; health care workers attitude/bias, method unavailability and client preference [25] and the focus offamily planning counseling for PLHIV was exclusively on condoms, with very little discussion of other contraceptive methods [14] [15].

WHO medical eligibility criteria do not preclude HIV-positive women from using highly effective contraceptive methods such as pills or an IUCD [4] [8] and ideally, providers should be aware that all methods can be used by HIV-positive women, except in very specific cases related to particular drug regimens, clinical stage of the disease, or risk of sexually transmitted infections [21] [22]. But study conducted in five African countries implies that, providers have reservations to counsel and deliver hormonal methods as well as IUCDs to HIVpositive women [21].

In this study, participants who have been counseled for FP by their ART providers/counselor are two and half times more likely to use contraceptive currently than those participants who have not been ever counseled about. Similarly studies conducted in Uganda [23], Ivory-coast [26] and other countries [13] [15] [24] indicated that discussion of family planning with a health worker were significantly associated with use of contraceptive. Therefore, integration of FP service into chronic care service may work best to increase method mix and increase FP uptake, in order to achieve the goal of prevention of unintended pregnancy among HIV positive women and maximum reduction of new pediatric HIV infection. The evidence from South Wollo zone in Ethiopia demonstrated high demand for long and permanent contraception methods by improving the availability of the methods and through appropriate awareness creation programs [27].

As evidenced elsewhere, educated women have tended to use contraceptive than women with little or no education [19] [23] [28] [29]. This pattern is also evident in this study as well. Those participants with primary and secondary educational status were more likely to use contraceptive than those who have no formal education. This could be due to the fact that educated women are better informed about the various methods and their availability and have greater access to family planning.

Spousal communication is an important precursor to the adoption of family planning methods. According to the EDHS 2000 analysis, Seven percent of women who have never discussed family planning with their husband use a method of contraception compared to $27 \%$ of women who discuss family planning once or twice and $40 \%$ of women who discuss family planning more often [30]. Several studies indicate that discussion with partner about FP or male involvement in FP decision; have found to be associated with increased contraceptive use among HIV positive women [12] [14] [23] [24]. In this study, as compared to those participants who decides about contraceptive use jointly with their partner, those who used to decide by themselves are less likely to use contraceptive. This finding is supported with the study conducted in Jimma, south west Ethiopia, irrespective of 
HIV status [31]. Hence, this study indicates that spousal/partner agreement remains an important area for utilization of FP in HIV positive women.

Women's attitude towards family planning impacts their willingness to use a method of contraception. In this study, those HIV positive women who are unable to define their attitude towards "safety of most contraceptive methods" were less likely to use contraceptive compared to those who have positive attitude. Other studies have also indicated that negative attitude and perception are barriers to family planning utilization [32].

In this study, those participants who have no fertility desire were more likely to use contraceptive than those who have fertility desire. This is similar with the finding of the study conducted at Hossana town, Ethiopia [33] and Soweto, South Africa [34].

Those women whose partners have no fertility desire were less likely to use contraceptive than those participants whose partners have a fertility desire. This finding is relatively similar with the study conducted in Uganda [32]. But it seems inconsistent with what has been indicated previously in many studies, where partner fertility desire seems to increase women fertility desire, which in turns decrease contraceptive utilization [24] [25] [32]. One possible explanation for this could be, the evidence that, spousal discussion about family planning and contraceptive practice has found to be crucial for the wider acceptance of contraceptive practice and lessening partners' fertility intention in developing countries [35]. Hence, as this is a cross-sectional study, it is unclear if one factor leads to another. The second possible explanation for this finding could be; fertility related decisions of HIV positive women are now mainly held based on the joint decision of the women and their partners rather than the mere decision of either the partner or the women themselves, as supported with the above finding regarding decision making about FP use. This explanation could be well addressed, if the fertility desire level of agreement were analyzed between the women and their partners.

\section{Conclusions}

This study has documented that the uptake of contraceptive use among HIV positive women is fairly high, compared to other studies conducted in Ethiopia. And it seems that sexually active HIV positive women are trying to prevent pregnancy by using different contraceptive methods, but utilization of most effective long acting contraceptive method is still very low.

Utilization of contraceptive is not affected by a complex web of socio-cultural factors like; by their marital status, religion, employment status, income, clinical HIV and ART status or cultural factors, rather mostly influenced by factors which are found under one umbrella and can be addressed as "one-stop-shop service". Hence, this study highlights it is possible to address most of contraceptive utilization predictor's and increase the uptake through provision of effective counseling about FP, child bearing and pregnancy issues to HIV positive women and their partners. What can be done during client's visit for their usual chronic is service, in the context of strong FP/HIV service integration.

\section{Recommendations}

Health care providers should give emphasis for counseling regarding all contraceptive including most effective long acting methods during provision of FP counseling to HIV positive women, in order to make contraceptive choice is based on fully informed decision. Child bearing and pregnancy issue should be clearly communicated and discussed well with HIV positive women and their partners, with the aim of increasing their PMTCT knowledge and have informed fertility decision.

Program managers and policy makers should ensure early intervention and regulation to reduce the financial cost of contraceptive among HIV positive women. In addition government policies and strategies in relation to family planning practice need to give emphasis for women education, empowerment and male involvement.

In addition, further research should be conducted to test the impact of integration efforts on outcomes such as; prevented unintended pregnancies, HIV-positive births averted and the reasons for the discrepancy between the observed increased contraceptive rate and high pregnancy rate.

\section{References}

[1] UNAID (2008) Report on Global AIDS Epidemic. UNAIDS, Geneva.

[2] WHO (2010) PMTCT Strategic Vision 2010-2015: Preventing Mother-to-Child Transmission of HIV to Reach the UNGASS and Millennium Development Goals. WHO, Geneva. 
[3] Hubacher, D., Mavranezouli, I. and McGinn, E. (2008) Unintended Pregnancy in Sub-Saharan Africa: Magnitude of the Problem and Potential Role of Contraceptive Implants to Alleviate It. Contraception, 78, 73-78. http://dx.doi.org/10.1016/j.contraception.2008.03.002

[4] Harvard School of Public Health (2010) The Pregnancy Intentions of HIV-Positive Women: Forwarding the Research Agenda Conference Report. Harvard School of Public Health, Boston.

[5] Mona, R., Trevor, A., Saira, S., Lena, C., Edward, D., Sharon, L., et al. (2013) Fertility Desires and Intentions of HIV-Positive Women of Reproductive Age in Ontario, Canada: A Cross-Sectional Study. Ontario, Canada.

[6] Rose, W. and Willard, C. (2009) Reproductive Choices for Women with HIV. Bulletin of World Health Organization, USA. http://www.who.int//entity/bulletin/en/

[7] Population Action International (2012) Promoting FP/RH-HIV/AIDS Integration: A Summary of Global Health Initiative Strategies in Ethiopia, Kenya, Tanzania, and Zambia. Population Action International, Washington DC, July, p. 8.

[8] Central Statistical Agency (2012) Ethiopia Demographic and Health Survey 2011. ICF International, Addis Ababa, March 2012.

[9] Federal Democratic Republic of Ethiopia (2012) Country Progress Report on HIV/AIDS Response: HAPCO. April.

[10] Tamene, W. and Fantahun, M. (2007) Fertility Desire and Family-Planning Demand among HIV-Positive Women and Men Undergoing Antiretroviral Treatment in Addis Ababa, Ethiopia. African Journal of AIDS Research, 6, 223-227. http://dx.doi.org/10.2989/16085900709490418

[11] Tesfaye, L., Admassu, M., Getachew, A. and Hardeep, R. (2013) Fertility Desires and Family Planning Demand among HIV-Positive Clients in Follow-Up Care at Antiretroviral Treatment Unit in Gondar University Hospital, Ethiopia. Vulnerable Children and Youth Studies: An International Interdisciplinary Journal for Research, Policy and Care, 7, 20-35. http://dx.doi.org/10.1080/09540121.2011.647114

[12] Haddad, L. (2011) Family Planning for Women with HIV on Antiretroviral therapy in Lilongwe, Malawi (Internet). New York.

[13] Ibrahim, K., Nigel, L., Akol, Z., Amandua, J., Kenneth, K., Stephen, K., et al. (2010) Strategies Used by Facilities in Uganda to Integrate Family Planning into HIV Care: What Works and What Doesn't. Africa Journal of Reproductive Health, 14, 149-150.

[14] Rhoda, K., Nazarius, M., Rosemary, K., Jolly, B., Lynn, A., Apolo, K., et al. (2011) Uptake of Family Planning Methods and Unplanned Pregnancies among HIV-Infected Individuals: A Cross-Sectional Survey among Clients at HIV Clinics in Uganda. Journal of the International AIDS Society, 14, 35. http://dx.doi.org/10.1186/1758-2652-14-35

[15] Chakrapani, V., Kershaw, T., Shunmugam, M., Newman, P.A., Cornman, D.H. and Dubrow, R. (2011) Prevalence of and Barriers to Dual-Contraceptive Methods Use among Married Men and Women Living with HIV in India. Infectious Diseases in Obstetrics and Gynecology, 2011, 376432.

[16] Regassa, T. and Fantahun, M. (2012) Fertility Desire and Reproductive Health Care Needs of Men and Women Living with HIV/AIDS in Nekemte, East Wollega, Ethiopia. Starjournal, 1, 31-38. www.starjournal.org

[17] Tadesse, L. and Belachew, A. (2012) Assessment of Fertility Desire and Family Planning Utilization among HIV Positive People Who Are on Antiretroviral Treatment, Asella Hospital, Arsi Zone, Oromia Region. AAU. May.

[18] Isabella, B. (2009) Contraceptive Utilisation and Associated Factors among HIV Positive Women in Mulago ISS Clinic. Diss. Makerere University, Kampala.

[19] Daire, O. (2011) Contraception Use among HIV Positive Women on Antiretroviral Therapy (ART) in Blantyre, Malawi. Nov. www.medcol.mw/

[20] Francis, O., Anke van der, K., Harriet, O., et al. (2012) Factors Associated with Unintended Pregnancy, Poor Birth Outcomes and Post-Partum Contraceptive Use among HIV-Positive Female Adolescents in Kenya. BMC Women's Health, 12, 34. http://www.biomedcentral.com/1472-6874/12/34

[21] Susan, A., Barbara, J., Jennifer, L., Emmanuel, M., Thomas, G. and Emily, K. (2010) Study of Family Planning and HIV Integrated Services in Five Countries: Final Report's. Family Health International, 54 p.

[22] WHO (2010) Medical Eligibility Criteria for Contraceptive Use 2010. 4th Edition, Department of Reproductive Health, World Health Organization, Geneva.

[23] Jianghong, L., et al. (2011) Family Planning among People Living with HIV in Post-Conflict Northern Uganda: A Mixed Methods Study. Conflict and Health, 5, 18. http://www.conflictandhealth.com/content/5/1/18 http://dx.doi.org/10.1186/1752-1505-5-18

[24] Egessa, J. (2010) Utilization of Family Planning Services among Sexually Active People Living with HIV/AIIDS in TasoTororo. www.docs.mak.ac.ug/

[25] USAID (2007) Measure Evaluation: A Guide for Monitoring and Evaluating Population-Health-Environment Programs. USAID, Washington DC. 
[26] Brou, H., et al. (2009) Contraceptive Use and Incidence of Pregnancy among Women after HIV Testing in Abidjan, Ivory Coast. PubMed Article, 57, 77-86. http://www.ncbi.nlm.nih.gov/pubmed

[27] Getachew, M., Alemseged, F., Abera, M. and Deribew, A. (2010) Factors Affecting Fertility Decisions of Married Men and Women Living with HIV in South Wollo Zone, Northeast Ethiopia. Ethiopian Journal of Health Development, 24, 7.

[28] Winnie, M., et al. (2012) Contraceptive Use and Associated Factors among Women Enrolling into HIV Care in Southwestern Uganda: Clinical study. Hindawi Publishing Corporation. Infectious Diseases in Obstetrics and Gynecology, 2012, Article ID: 340782. http://dx.doi.org/10.1155/2012/340782

[29] Berhane, Y., et al. (2013) Utilization of Modern Contraceptives among HIV Positive Reproductive Age Women in Tigray, Ethiopia: A Cross Sectional Study. ISRN AIDS, 2013, Article ID: 319724.

[30] Antenane, K. (2002) Attitudes toward Family Planning and Reasons for Nonuse among Women with Unmet Need for Family Planning in Ethiopia. MEASURE DHS+:ORC Macro; November 2002. www.measuredhs.com

[31] Hailei, A. and Enqueselassie, F. (2006) Influence of Women’s Autonomy on Couple’s Contraception Use in Jimma Town, Ethiopia. Ethiopian Journal of Health Development, 20, 145-151.

[32] Ward, V.M., Bertrand, J.T. and Puac, F. (1992) Exploring Sociocultural Barriers to Family Planning Among Mayans in Guatemala. International Family Planning Perspectives, 18, 59-65. http://dx.doi.org/10.2307/2133395

[33] Abebe, M., Addissie, A. and Regassa, T. (2012) Fertility Desire and Contraceptive Utilization among People Living with HIV/AIDS on ART, Hosanna Town, Southern Ethiopia. Star Journal, 1, 38-46. www.starjournal.org

[34] Kaida, A., Laher, F., Strathdee, S.A., Money, D., Janssen, P.A., et al. (2010) Contraceptive Use and Method Preference among Women in Soweto, South Africa: The Influence of Expanding Access to HIV Care and Treatment Services. PLoS ONE, 5, e13868. http://dx.doi.org/10.1371/journal.pone.0013868

[35] Beekle, A. and Mccabe, C. (2006) Awareness and Determinants of Family Planning Practice in Jimma, Ethiopia. International Nursing Review, 53, 269-276. http://dx.doi.org/10.1111/j.1466-7657.2006.00492.x 


\section{Appendix 1: Questionnaire}

Structured questionnaire on FP use and associated factors among HIV infected women enrolled at Government ART program at Bahir-dar town health facilities

\begin{tabular}{|c|c|c|c|}
\hline \multicolumn{4}{|c|}{ PART I: Demographic Characteristics } \\
\hline No & Questions & Categories & Skip \\
\hline 101 & How old are you? & _ (age in full years) & \\
\hline 102 & $\begin{array}{l}\text { Where is your current residence? } \\
\text { (write the name of residence in the blank space) }\end{array}$ & $\begin{array}{l}\text { 1. urban } \\
\text { 2. Rural }\end{array}$ & \\
\hline 103 & What is the highest educational level you completed? & $\begin{array}{l}\text { grade completed } \\
\text { 1. No formal education(Unable to read and write) } \\
\text { 2. No formal education (Able to read and write) } \\
\text { 3. Technical/Vocational certificate } \\
\text { 4. University/college diploma } \\
\text { 5. University/college degree or higher }\end{array}$ & \\
\hline 104 & What ethnic group do you belong to? & $\begin{array}{l}\text { 1. Amhara } \\
\text { 2. Tigre } \\
\text { 3. Oromo } \\
\text { Other (specify) }\end{array}$ & \\
\hline 105 & What is your religion? & $\begin{array}{l}\text { 1. Orthodox } \\
\text { 2. Muslim } \\
\text { 3. Protestant } \\
\text { 4. Catholic } \\
\text { Other (specify) }\end{array}$ & \\
\hline 106 & What is your current occupation status? & $\begin{array}{l}\text { 1. Un employed/House wife/ } \\
\text { 2. Daily laborer } \\
\text { 3. Merchant } \\
\text { 4. Government employee } \\
\text { 5. Private organization/sector employee } \\
\text { 6. Student } \\
\text { 7. House servant } \\
\text { 8. Sex worker } \\
\text { 9. Farmer } \\
\text { 10. No response } \\
\text { Other (specify) }\end{array}$ & \\
\hline 107 & What is your current marital status? & $\begin{array}{l}\text { 1. Married } \\
\text { 2. cohabited partner } \\
\text { 3. Non-cohabited partner } \\
\text { 4. Divorced/separated } \\
\text { 5. Single } \\
\text { 6. Widowed/ } \\
\text { 7. No response } \\
\text { Other (specify) }\end{array}$ & \\
\hline 108 & What is the total monthly family income? & $\begin{array}{l}\text { Your own income (_ }) \text { ETB } \\
\text { Husband income (_ } \\
\text { Other source of income (__ ETB } \\
\text { 1. no income } \\
\text { 2. Don't know } \\
\text { 3. no response }\end{array}$ & \\
\hline 109 & $\begin{array}{l}\text { What is the highest educational level your spouse/partner } \\
\text { completed? }\end{array}$ & $\begin{array}{l}\text { grade completed } \\
\text { 1. No formal education(Unable to read and write) } \\
\text { 2. No formal education (Able to read and write) } \\
\text { 3. Technical/Vocational certificate } \\
\text { 4. University/college diploma } \\
\text { 5. University/college degree or higher }\end{array}$ & \\
\hline
\end{tabular}

PART II. Information on Family planning counseling, use, demand and choice

201 Have you ever heard of any contraceptive methods that

1. Yes couple can use to avoid or delay pregnancy? 
If yes to Q. 201, which methods have you heard about? (Do not read the list. Check all that apply Probe: anything else)

Where did you get the information about contraceptive?

Have you (your partner) ever used any contraceptive methods before your HIV diagnosis?

If yes for Q 204, specify the method you / your partner used?

( more than one answer is possible)

Have you (your partner) ever used any contraceptive methods after your HIV diagnosis?

If yes for Q 206, specify the method you or your partner used?

( more than one answer is possible)

Have you ever been counseled by your ART provider/counselor about any contraceptive methods?

About which method does the ART provider/counselor/counseled you? /more than one answer is possible/

1. Female sterilization/Tubal ligation

2. Male sterilization/Vasectomy

3. condom

4. Pills (OCP)

5. injectable

6. IUD

7. Implants

8. Calendar/

9. LAM

10. Absistence

Other (specify)

1. Mass media

2. Health professionals

3. friends

4. families

Other (specify)

1. Yes 3. I don't remember

2. No 4. No response

1. Female sterilization/Tubal ligation

2. Male sterilization/Vasectomy

3. condom

4. Pills (OCP)

5. injectable

6. IUD

7. Implants

8. Calendar/rhythm method

9. LAM

10. Absistence

Other(specify)

1. Yes

2. No

3. I don't remember

4. No response

1. Female sterilization/Tubal ligation

2. Male sterilization/Vasectomy

3. condom

4. Pills (OCP)

5. injectable

6. IUD

7. Implants

8. Calendar/rhythm method

9. LAM

10. Absistence

Other(specify)

1. Yes

2. No

3. I don't remember

4. No response

Other(specify)

1. Female sterilization/Tubal ligation

2. Male sterilization/Vasectomy

3. condom

4. Pills (OCP)

5. injectable

6. IUD

7. Implants

8. Calendar/rhythm method

9. LAM

10. Absistence

11. Dual contraceptive method

Other (specify)

1. Yes

2. No

Other (specify) 
If yes to Q no 210, what methods have you been provided?

Are you (your partner) using any contraceptive methods currently?

Would you specify the method you (your partner) are using now? (more than one answer is possible)

For what purpose are you (your partner) using contraceptive now?

Why do you choose the current FP method?

Where do you get the (current contraceptive method in $Q$ 212) last time?
1. condom

2. Pills (OCP)

3. injectable

4. IUD

5. Implants

6. Emergency contraceptive

Other (specify)

1. Yes

2. No

1. Female sterilization/Tubal ligation

2. Male sterilization/Vasectomy

3. condom

4. Pills (OCP)

5. injectable

6. IUD

7. Implants

8. Calendar/rhythm method

9. LAM

Other (specify)

1. For spacing birth

2. For limiting birth

Other (specify)

1. Health professional advice

2. Because it is suitable to my health

3. From my friends experience and advice

4. Partner preference

Other (specify)

1. ART clinic in this facility

2. FP clinic with in this facility

3. other governmental Hospital

4. other governmental health center

5. other governmental health post

6. Private clinic/hospital

7. Pharmacy /drug vendors

8. Community Health/Health extension workers

9. NGO clinics/ FGA

10. Shop

Other (specify)

1. I didn't pay/free

birr

2. Don't know

1. Want to have child/children

2. Don't know it is indicated to HIV positive women

3. Fear of FP method interference with my ART drug

4. Religious prohibition

5. Partner/spouse not willing to use contraceptive

6. Fear of side effects

7. Cost too much

Other reason (specify)

1. Yes

2. No

3. I am not sure

Other (specify) 
If yes to Q219, which contraceptive method is you (your partner) intend to use?

(more than one answer is possible)

Have you ever been referred for FP service by your counselor/ART provider?

where have u been referred to get FP service by your counselor/ART provider?

Is there any cultural practice in your community that prevents you from using contraceptive?

If yes, please mention some of the most common cultural practices that prevent you from using contraceptive

Have you ever discussed with your partner about using any contraceptive method to delay or avoid pregnancy use?

Would you say that using contraception is mainly yours, your partner or joint decision?

Most Contraceptive methods are safe for use by women

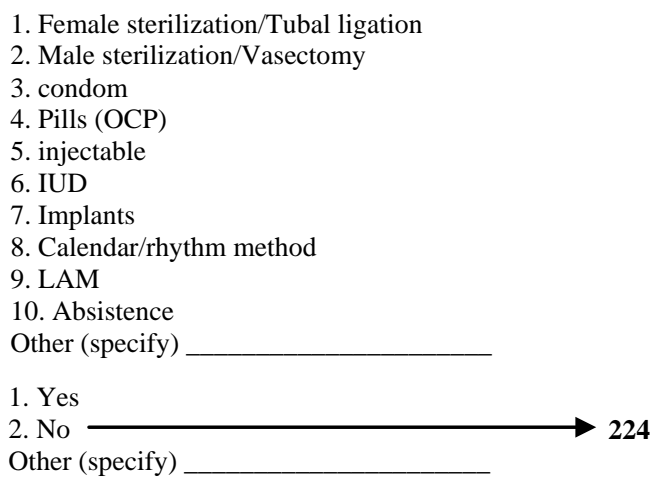

1. FP clinic with in this facility

2. Other governmental health facilities

3. Private clinic/hospital

4. Pharmacy /Drug vendor

5. NGO clinics/FGA

Other (specify)

1. method unavailable at the facility/method stock out

2. Health professional was busy

3. I prefer to be referred to other site

4. I don't know the reason

5. I don't remember Other (specify)

1. ART clinic in this facility

2. FP clinic with in this facility

3. other governmental Hospital

4. other governmental health center

5. other governmental health post

6. Private clinic/hospital

7. Pharmacy /drug vendors

8. NGO clinics/ FGA

9. Shop

Other (specify)

1. Yes

2. No

3. I don't know

Other (specify)

1. Yes

2. No

3. I don't have a partner

Other (specify)

1. My decision

2. My partner decision

3. Joint decision

Others (specify)

1. Strongly agree

2. Somewhat agree

3. No opinion

4. Somewhat disagree

5. Strongly disagree

No response

Part III: Information about HIV diagnosis, ART treatment condition and knowledge about MTCT and PMTCT month/s

1. Don't remember 2. No response 
302 Have you started to take ART treatment?

303 when did you start receiving ART treatment?

In your opinion, how is your perceived health status after you start taking ART?

All in all, how would you describe your state of health ays? Would you say it is /read option 1-5/

Does HIV transmit from mother to child?

If Yes to Q 306, When do you think HIV is transmitted

Is there any medication/intervention, which may help to prevent mother to child HIV transmission?

If yes to Q 308, How can the risk of passing HIV can be minimized/prevented from HIV positive woman to her child?

(Do not read the list. Check all that apply. Probe: anything else)

If yes to Q 309, what is your opinion regarding the effectiveness of the current PMTCT

310 medication/interventions in averting HIV positive births? would you say

(read option 1-5)

Where did you get the information about mother to child transmission of HIV infection and/or its prevention?

\section{Yes}

2. No

3. No response

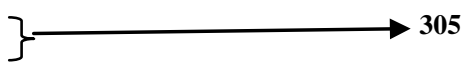

1. Don't remember month/s

2. No response

1. Improved

2. No change

3. getting worse

No response

1. Very good

2. Good

3. fair

4. poor

5. Very poor

1. Yes

2. No

3. I Don’t know

1. During pregnancy

2. During labor and deliver

3. Through breast feeding

4. I Don't know

Other (specify)

1. Yes

2. No

3. I don't know

1. Avoiding pregnancy

2. Provision of ARV medication to mother

3. Provision of ARV medication to infant

4. Deliver at health facilities

5. replacing BF with formula feeding

6. Eclusive breast feeding for six month

7. I Don't know

Others (specify)

1. strongly agree

2. Agree

3. No opinion

4. Disagree

5. Strongly disagree

1. Health care providers

2. Mass media

3. Mother support group or other similar meet-

ings

4. HIV positive pregnant women/ friend

5. Other friends and relative

Other (specify)

\section{Part IV Information on reproductive characteristics}

401 How many live births have you had in your lifetime?

1.

2.a)_ Son b) (total number of live children)

3.Never give a live birth

4. No response

1. of alive children

402 How many of them are alive now?

2. a) Son b) Daughter

No response

403 Do you desire to have a child in the future?

1. Yes

2. No 406

404 If yes, How many children do you want to have in the future?

1.

(total number of children)

2.a)___ Son b) ___ Daughter 
How soon do you want to have a child?

Does your spouse/partner desire to have a child in the future?

Have you ever become pregnant after you know your HIV test result?

how many times you become pregnant after you know your HIV status?

Would you tell me how many of those pregnancies were wanted or not wanted by the time you became pregnant?

what was the outcome of the last pregnancy?

What was the HIV status of the last born baby?

Have you ever discussed with your ART

412 provider/counselor about issues related with pregnancy and child bearing?

If Q 407 is yes, did the

413 provider adequately cover the issues?

Would you like to discuss with your ART

414 provider/counselor about pregnancy and child bearing in advance? month or year

1. I don't know/I am not sure

No response

1. Yes

2. No

3. I don't know/I am not sure

4. I don't have spouse/partner

No response

1. Yes

2. No

No response

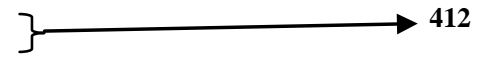

( number of pregnancies)

1) __ of them were "wanted"

2) of them were "unwanted"

3. I don't remember

NO response

1. Spontaneous abortion

2. Medical/other mode of wanted abortion

3. still birth

4. live birth

No response

Other (specify)

1. HIV positive

2. HIV negative

3. Not yet confirmed/known

No response

Other (specify)

1. Yes

2. No

3. I don't remember

No response

1. Yes

2. No

No response

1. Yes

2. No

No response

\section{Part V Information on sexuality and condom use}

501 What was the age of your first sexual debut?

1. I don't remember

(age in full years)

No response

1. Yes

2. No months?

503 How many different partners have you had sexual intercourse with during the last 12 month?

1. I don't remember

2. no response

Other

1. Always

2. Usually

3. Sometimes

4. Rarely

5. Never used

No response

1. Last one week

2. Last one month

3. Last 1 - 6 months

4. Last 6 - 12 months

5. I don't remember

6. No response 


\begin{tabular}{|c|c|c|}
\hline 506 & $\begin{array}{l}\text { Have you used condom during your recent last sexual } \\
\text { intercourse? }\end{array}$ & $\begin{array}{l}\text { 1. Yes } \\
\text { 2. No } \\
\text { 3. I Don't remember } \\
\text { 4. No response } \\
\text { Other (specify) }\end{array}$ \\
\hline 507 & If yes to Q 506, what was the reason you used condom? & $\begin{array}{l}\text { 1. To prevent pregnancy } \\
\text { 2. To prevent other Sexually transmitted infec- } \\
\text { tions } \\
\text { 3. My partner HIV status was negative } \\
\text { 4. To protect myself from acquiring other strains } \\
\text { of HIV virus } \\
\text { 5. Just Health professional's advice } \\
\text { Other (specify) }\end{array}$ \\
\hline 508 & $\begin{array}{l}\text { Did you disclose your sero status to your current } \\
\text { partner/spouse? }\end{array}$ & $\begin{array}{l}\text { 1. yes } \\
\text { 2. No } \\
\text { 3. Don't have spouse/partner currently } \longrightarrow 511 \\
\text { Other (specify) }\end{array}$ \\
\hline 509 & $\begin{array}{l}\text { Do you know the HIV status of your current sexual } \\
\text { partner/spouse? }\end{array}$ & $\begin{array}{l}\text { 1. yes } \\
\text { 2. No } \\
\text { 3. No response }\end{array}$ \\
\hline 510 & If yes, what was his test result? & $\begin{array}{l}\text { 1. HIV positive } \\
\text { 2. HIV negative } \\
\text { 3. No response }\end{array}$ \\
\hline 511 & $\begin{array}{l}\text { What is your opinion regarding the provision of FP } \\
\text { service in ART clinic? } \\
\text { (Read option 1-5) }\end{array}$ & $\begin{array}{l}\text { 1. Strongly support } \\
\text { 2. Support } \\
\text { 3. No opinion } \\
\text { 4. Oppose } \\
\text { 5. Strongly oppose }\end{array}$ \\
\hline
\end{tabular}

\section{Thank you very much for your Cooperation!}

